\section{REPEATED DOSES OF ANTENATAL CORTICOSTEROIDS FOR WOMEN AT RISK OF PRETERM BIRTH REDUCE SIZE AT BIRTH}

\author{
J. Stålnacke ${ }^{1}$, H. Norberg ${ }^{2}$, R. Diaz Heijtz ${ }^{3}$, H. \\ Forssberg $^{3}$, M. Norman ${ }^{2}$ \\ ${ }^{1}$ Dept of Psychology, Stockholm University, ${ }^{2}$ Dept \\ of Clinical Science, Intervention and Technology, \\ ${ }^{3}$ Dept of Woman and Child Health, Karolinska \\ Institutet, Stockholm, Sweden
}

Objective: Repeat dosesofantenatal corticosteroids reduce occurrence of neonatal lung disease in preterm infants. The primary objective of this study was to evaluate longer-term benefits and risks with such intervention. Here we report effects on neonatal anthropometry.

Methods: Cohort study of 94 subjects (59 boys, mean gestational age (GA) at first exposure for corticosteroids $28.7 \mathrm{w}, \mathrm{GA}$ at birth $34.0 \mathrm{w}$ ) born 1983-1995 and exposed to 2-9 doses of antenatal betamethasone (first $24 \mathrm{mg}$ followed weekly with an additional $16 \mathrm{mg}$ until delivery or $34 \mathrm{w}$ GA). Exposure data were retrieved from case record files. Information on other risk factors or potential confounders (maternal age, height, parity, smoking, preeclampsia, and multiple pregnancy), and outcome was collected from the Swedish Medical Birth Registry.

Results: In univariate analyses, SD-scores for birth weight $(\mathrm{BW})$, birth length $(\mathrm{BL})$, and head circumference $(\mathrm{HC})$ decreased from $-0.25,-0.11$, and +0.25 in infants exposed to 2 doses, to -0.99 , -1.03 , and -0.22 , respectively, in infants exposed to $\geq 4$ doses of antenatal corticosteroids ( $p=0.05-0.07$ ). In multivariate analyses, $\geq 4$ doses $(n=40)$ was associated with lower SD-scores for BW $(p=0.01)$, $\operatorname{BL}(p=0.007)$, and $\mathrm{HC}(p=0.04)$ as compared to SD-scores found after 2-3 doses of antenatal corticosteroids $(n=54)$. The size of the effect from $\geq 4$ doses of antenatal steroids on BW and BL was comparable to the reduction in birth size seen in twins, and on $\mathrm{HC}$ to that seen after maternal smoking.

Conclusion: Multiple doses of antenatal corticosteroids are associated with a reduction in $\mathrm{BW}, \mathrm{BL}$ and $\mathrm{HC}$.

\section{DIFFERENCES IN ORGAN DYSFUNCTIONS BETWEEN NEONATES AND OTHER CHILDREN}

S. Leteurtre ${ }^{1}$, N. Bestati ${ }^{1}$, A. Duhamel ${ }^{2}$, F. Proul $x^{3}$, B. Grandbastien ${ }^{4}$, J. Lacroix ${ }^{3}$, F. Leclerc ${ }^{1}$, on behalf of the PELOD Group

${ }^{1}$ PICU, Jeanne de Flandre Hospital, ${ }^{2}$ Biostatistic Department, CHR\&U, Lille, France, ${ }^{3} \mathrm{PICU}$, Sainte-Justine Hospital, Montréal, QC, Canada, ${ }^{4}$ Department of Epidemiology and Public Health, CHR\&U, Lille, France

The PEdiatric Logistic Organ Dysfunction (PELOD) score has been validated as a score to describe and quantify the severity of organ dysfunctions (ODs). Several neonatal pathophysiological and immunological particularities make a rationale for differences in ODs between neonates and other children (non-neonates).

Objective: To find out if there are important differences in mortality, OD incidence and OD contribution to mortality between neonates (age $<28$ days) and non-neonates, using the PELOD score.

Methods: Prospective, observational study in seven PICUs of university-affiliated hospitals (09/98 02/2000). No intervention was done.

Results: 1806 patients were included, 171 (9.5\%) were full-term neonates. Mortality rate and incidence of MODS were higher in neonates than in nonneonates ( $14.6 \%$ vs. $5.5 \%, p<10^{-7} ; 75.4 \%$, vs. $50.9 \%$, $\mathrm{p}<10^{-4}$ respectively). Daily PELOD (dPELOD) scores were significantly higher in neonates from day 1 to day 4. Daily cardiovascular, respiratory and renal dysfunction scores from day 1 to day 4 , and the entire stay dysfunction scores of these three organs were significantly higher in neonates than in non-neonates. The ODs that significantly contributed to mortality in neonates were neurological, cardiovascular, and hepatic dysfunctions. In non-neonates, all ODs significantly contributed to mortality.

Conclusion: Our data demonstrate that mortality in neonates was higher as compared with nonneonates. Neurological, cardiovascular, and hepatic dysfunctions were the only significant contributors to neonatal mortality, while other ODs were also associated with mortality in non-neonates.

(PELOd group: we thank Jacques Cotting, Ronald Gottesman, Ari Joffe, Bendicht Wagner, Philippe Hubert, Alain Martinot for their contribution in data collection) 